\title{
Evaluation of mechanical properties of five cements for orthodontic band cementation
}

\author{
Diego Andrei Aguiar(a) \\ Daltro Enéas Ritter ${ }^{(a)}$ \\ Roberto Rocha ${ }^{(a)}$ \\ Arno Locks ${ }^{(a)}$ \\ Adriano Ferreti Borgatto ${ }^{(b)}$
}

(a) Programa de Pós-Graduação em Odontologia, Univ Federal de Santa

Catarina - UFSC, Florianópolis, SC, Brazil.

(b) Departamento de Informática e Estatística, Univ Federal de Santa Catarina - UFSC,

Florianópolis, SC, Brazil.
Declaration of Interests: The authors certify that they have no commercial or associative interest that represents a conflict of interest in connection with the manuscript.

\section{Corresponding Author:}

Daltro Enéas Ritter

E-mail:daltroritter@hotmail.com

Submitted: Sep 04, 2012

Accepted for publication: Dec 03, 2012

Last revision: Dec 17, 2012

\begin{abstract}
The aim of this in vitro study was to compare the flexural, compressive and diametral tensile strengths of five cements used in orthodontics for band cementation. Twelve specimens of each cement were tested: 1 - GC Fuji Ortho Band (FJ), GC America Inc.; 2 - Meron (MR), Voco; 3 - Multi-Cure Glass Ionomer Band Cement (MC), 3M Unitek; 4 Band-Lok (BL), Reliance Orthodontic Products; and 5 - Ketac Cem (KC), 3M ESPE. The results (mean) for diametral tensile strength were: 10.51 $\mathrm{MPa}(\mathrm{FJ}), 9.60 \mathrm{MPa}$ (MR), 20.04 MPa (MC), 42.80 MPa (BL), and 4.08 $\mathrm{MPa}(\mathrm{KC})$. The results for compressive strength were (in the same order): 64.50 MPa, 77.71 MPa, 94.21 MPa, 193.88 MPa, and 81.93 MPa. The results for flexural strength were (in the same order): $20.72 \mathrm{MPa}$, 25.84 $\mathrm{MPa}$, 53.41 MPa, 137.41 $\mathrm{MPa}$, and 20.50 MPa. The statistical analysis was performed by two-way ANOVA and Tukey tests with p-value $\leq 0.05$. In terms of diametral tensile strength, BL showed the highest strength statistically, and MC, the second highest. In terms of compressive tensile strength, BL showed the highest strength statistically, and FJ did not attain the minimum recommended strength. In terms of flexural tensile strength, BL cement was superior to $\mathrm{MC}$, and $\mathrm{MR}, \mathrm{FJ}$ and $\mathrm{KC}$ were equivalent and inferior to $\mathrm{BL}$ and $\mathrm{MC}$.
\end{abstract}

Descriptors: Basic Research; Dental Materials; Dental Cements.

\section{Introduction}

The use of direct bonded bands decreased considerably after polymeric adhesives for orthodontic bracketing were developed. However, these bands still represent a valuable resource for some teeth, e.g., molars, and are frequently made use of. Failure of molar tubes bonded with either a chemically cured or light-cured adhesive is considerably higher than the failure of molar bands cemented with glass ionomer cement. ${ }^{1}$ Band retention is mechanically influenced by the manner in which bands are adapted on teeth, and by the properties of the cements used. ${ }^{2-4}$

Today, the cements most widely used to cement molar bands are conventional glass ionomers (CGI), which have significant advantages, such as constant fluoride release and uptake, microbial inhibition, chemical adhesion to teeth and to metal, ${ }^{5-10}$ low thermal coefficient of expansion ${ }^{6}$ and low solubility. ${ }^{11}$ The introduction of light polymerized systems enhanced initial CGI resistance. ${ }^{7} \mathrm{McCabe}^{12}$ separates these most widely used cements into the following categories: 
- Modified Composites,

- Resin Modified Glass Ionomer Cements (RMGIC) and

- Compomers.

Modified Composites are cured by light polymerization; they contain glass particles that are chelated in an attempt to release fluoride (ex.: BandLok). RMGIC are cured by an acid-base reaction, and may optionally be light activated; they are composed of composite and glass ionomer components (ex.: Fuji Ortho Band, 3M Multi-Cure Glass Ionomer Cement). Compomers are cured by light polymerization reaction; although they release less fluoride than RMGICs, their cariostatic properties are maintained (ex.: Ultra Band-Lok).

Currently, RMGICs appear to offer the best balance between fluoride release, oral environment fluoride uptake and greatest clinical durability for patients with high caries risk. ${ }^{13}$ They are also light polymerized, achieve maximum resistance in less time $^{14}$ and appear to be more resistant than CGI. ${ }^{7}$

However the literature shows that there is insufficient high-quality evidence to confirm the most effective adhesive for attaching orthodontic bands to molar teeth. ${ }^{2,3}$ Because of the great variety of different glass ionomers recently available on the market, more research is needed to compare their mechanical behavior to support their clinical use.

The objective of this study was to evaluate the compressive, diametral tensile and flexural strengths of 5 materials used to cement orthodontic bands.

\section{Methodology}

The cements submitted to mechanical tests are specified in Table 1.

\section{Flexural strength test}

Twelve specimens of each cement were randomly made with a two-part metallic matrix, measuring $25 \mathrm{~mm}$ by $2 \mathrm{~mm}$ in length and height, respectively, according to ISO $^{15}$ (International Organization for Standardization) Standard 4049.

The cement specimens were mixed according to the manufacturer's recommendations and placed in the matrix over Mylar strips. After insertion of the material, another Mylar strip was placed on the top surface followed by another glass slab pressed manually to obtain a regular surface. ${ }^{16}$ After curing at the recommended time and without adding pressure, the specimens and the matrix were immersed in distilled water at $37^{\circ} \mathrm{C}$ for 15 minutes. The specimens were then ground and polished with 600 grit sand paper, and stored in water at $37^{\circ} \mathrm{C}$ for 24 hours. The flexural strength was determined by a three point test using an Instron Universal Test Machine, model 4444 (Instron Corp., Canton, USA). This device is in agreement with ISO Standard $4049 . .^{15}$ The flexural strength was calculated in $\mathrm{MPa}$, using the following equation: ${ }^{15}$

\section{Flexural resistance $(\mathrm{MPa})=3 \mathrm{Fd} / 2 w h^{2}$}

where

$F$ is the maximum load exerted on the specimens $(\mathrm{N})$,

$d$ is the distance between supports $(\mathrm{mm})$, $w$ is the width of the sample $(\mathrm{mm})$ and

$h$ is the height of the sample (mm).

\section{Compressive and diametral tensile strength tests}

Twelve cylindrical specimens of each cement

Table 1 - Materials used in this research.

\begin{tabular}{l|l|l|l|l|l}
\hline Materials & $\begin{array}{l}\text { GC Fuji Ortho } \\
\text { Band (FJ) }\end{array}$ & Meron (MR) & $\begin{array}{l}\text { Multi-Cure Glass lonomer } \\
\text { Band Cement (MC) }\end{array}$ & Band-Lok (BL) & Ketac Cem (KC) \\
\hline Serial number & Lot. 0703051 & Lot. 460314 & Lot. 7EB/7FR & Lot. 076304 & Lot. 162094 \\
\hline Kind of material & ARMGI & CGI & PRMGI & PMC & CGI \\
\hline Manufacturer & $\begin{array}{l}\text { GC America Inc., } \\
\text { Costa Mesa, USA }\end{array}$ & $\begin{array}{l}\text { Voco, Cuxhaven, } \\
\text { Germany }\end{array}$ & 3M Unitek, St Paul, USA & $\begin{array}{l}\text { Reliance Orthodontic } \\
\text { Products, Itasca, USA }\end{array}$ & 3M Espe, St Paul, USA \\
\hline
\end{tabular}

CGI: auto polymerized conventional glass ionomer cement. ARMGI: auto polymerized resin modified glass ionomer cement. PRMGI: photo polymerized resin modified glass ionomer cement. PMC: photo polymerized polyacid modified composite. 
were made to test compressive strength, and the same number were made to test diametral tensile strength, using a two-part metallic matrix, measuring $6 \mathrm{~mm}$ in height and $4 \mathrm{~mm}$ in diameter, according to ADA specification \#66 dated $1994 .{ }^{17}$ The same procedures of mixing and final preparation of specimens used to perform the flexural strength test were used to perform the compressive strength and the diametral tensile strength tests. Furthermore, the specimens for these tests were tested in the same Instron machine. The specimens were positioned vertically to their long axis for the compressive strength test, and horizontally to their long axis for the diametral tensile strength test.

The compressive strength values were calculated in $\mathrm{MPa}$, according to the following formula: ${ }^{17}$

\section{Compressive strength $(\mathrm{MPa})=4 F / \pi d^{2}$}

where

$F$ is the fracture load $(\mathrm{N})$ and

$d$ is the sample diameter.

The diametral tensile strength $(\mathrm{MPa})$ was calculated using the following formula: ${ }^{17}$

\section{Diametrical traction tension $(\mathrm{MPa})=2 \mathrm{~F} / \pi d L$}

where

$F$ is the fracture load $(\mathrm{N})$,

$d$ is the sample diameter $(\mathrm{mm})$ and

$L$ is the sample length $(\mathrm{mm})$.

\section{Statistical analysis}

One-way ANOVA (analysis of variance) was applied for each mechanical test, using PASW 18.0 software (IBM Corporation, New York, USA), where the isolated factor was cement group. Because the F-test for each one-way ANOVA detected significant statistical differences ( $\mathrm{p}$-value $\leq 0.05$ ) among the means of each cement group for each mechanical test, the Tukey test was applied to determine which cement groups were statistically different.

\section{Results}

The diametral tensile strength results are pre-
Table 2 - Results for diametral tensile strength. Means followed by the same letter do not differ according to the Tukey test; significance level of $5 \%$ ( $p$-value $>0.05)$.

\begin{tabular}{c|c|c|c|c|c}
\hline \multirow{2}{*}{$\begin{array}{c}\text { Mechanical } \\
\text { test }\end{array}$} & \multicolumn{5}{|c}{ Cement } \\
\cline { 2 - 6 } & FJ & MR & MC & BL & KC \\
\hline Diametral & 10.51 & 9.60 & 20.04 & 42.80 & 4.08 \\
tensile strength & $\mathrm{b}$ & $\mathrm{b}$ & $\mathrm{c}$ & $\mathrm{d}$ & $\mathrm{a}$ \\
\hline
\end{tabular}

Table 3 - Results for compressive strength. Means followed by the same letter do not differ according to the Tukey test; significance level of $5 \%$ ( $p$-value $>0.05)$.

\begin{tabular}{|c|c|c|c|c|c|}
\hline \multirow{2}{*}{$\begin{array}{c}\text { Mechanical } \\
\text { test }\end{array}$} & \multicolumn{5}{|c|}{ Cement } \\
\hline & FJ & MR & $M C$ & $\mathrm{BL}$ & $\mathrm{KC}$ \\
\hline $\begin{array}{c}\text { Compressive } \\
\text { strength }\end{array}$ & $\begin{array}{c}64.50 \\
a\end{array}$ & $\begin{array}{c}77.71 \\
a b\end{array}$ & $\begin{array}{c}94.21 \\
c\end{array}$ & $\begin{array}{c}193.88 \\
d\end{array}$ & $\begin{array}{c}81.93 \\
b c\end{array}$ \\
\hline
\end{tabular}

Table 4 - Results for flexural strength. Means followed by the same letter do not differ according to the Tukey test; significance level of $5 \%$ ( $p$-value $>0.05)$.

\begin{tabular}{c|c|c|c|c|c}
\hline \multirow{2}{*}{$\begin{array}{c}\text { Mechanical } \\
\text { test }\end{array}$} & \multicolumn{5}{|c}{ Cement } \\
\cline { 2 - 6 } & FJ & MR & MC & BL & KC \\
\hline $\begin{array}{c}\text { Flexural } \\
\text { strength }\end{array}$ & $\begin{array}{c}20.72 \\
\text { a }\end{array}$ & $\begin{array}{c}25.84 \\
\text { a }\end{array}$ & $\begin{array}{c}53.41 \\
\text { b }\end{array}$ & $\begin{array}{c}137.41 \\
\text { c }\end{array}$ & $\begin{array}{c}20.50 \\
\text { a }\end{array}$ \\
\hline
\end{tabular}

sented in Table 2. The compressive strength results are described in Table 3, and the flexural strength results are shown in Table 4 .

\section{Discussion}

Most material-related clinical failures occur because of the low tensile resistance of the material. ${ }^{18}$ The diametral tensile strength (DTS) test is an adaptation of the tensile strength test, since it is impossible to perform tensile strength tests on brittle materials, like glass ionomer cements. ${ }^{19}$ In the DTS test, a compressive force is applied to the cylinder over its diameter. In this study, Band-Lok (BL) cement was found to be statistically superior over the other tested cements, showing an average (av.) strength of $42.80 \mathrm{MPa}$ (Table 2). Multi-Cure Glass Ionomer Band Cement (MC) had the second highest average (20.04 MPa) in this test. It was statistically different from Meron (MR) cement (av. 9.60 MPa) and Fuji Ortho (FJ) cement (av. 10.51 MPa), which were similar. Ketac Cem (KC) cement (av. $4.08 \mathrm{MPa}$ ) had the 
lowest DTS average statistically. These results indicate that BL cement has the highest cohesive properties and is the most resistant to fracture loads, followed by Multi-Cure.

Farret et al. ${ }^{16}$ found no statistical difference in DTS tests for Ketac Cem (7.41 MPa) and Meron (6.05 MPa) (both conventional glass ionomers). In our study, Meron was statistically superior to Ketac Cem for DTS, compared to resin modified glass ionomer cement $(\mathrm{FJ})$, but was inferior to $\mathrm{BL}$ and $\mathrm{MC}$ statistically (Table 2).

Millett et al. ${ }^{4}$ compared the mean retentive strength of microetched orthodontic bands cemented to extracted human third molars with a modified composite, a resin-modified glass ionomer cement, and a conventional glass ionomer cement. The mean retentive strength of the modified composite $(0.415$ $\mathrm{MPa}$ ) was significantly less than that of either the resin-modified (1.715 $\mathrm{MPa})$ or the conventional glass ionomer cements $(1.454 \mathrm{MPa} ; \mathrm{p}<.001)$. Although modified composites had higher DTS levels in our study, Millett et al. ${ }^{4}$ laboratory results shows that their retentive strength was lower than that of glass ionomer cements (conventional and resin modified glass ionomer). Because both our study and that of Millett et al. ${ }^{4}$ used different methodologies, a comparison of direct results should be avoided and interpreted with caution.

The compressive strength (CS) test allows a good representation of the mechanical integrity of different materials, and can be used to test brittle materials like glass ionomer cements. ${ }^{20} \mathrm{CS}$ is an extremely important factor, particularly regarding mastication. In determining CS, two axial forces are applied to the material in opposite directions, thus bringing its molecular components closer together. ${ }^{21}$ In the present study BL cement (av. 193.88 MPa) showed statistically superior values, in comparison to other cements tested (Table 3). MC (av. $94.21 \mathrm{MPa}$ ) was similar to $\mathrm{KC}(81.93 \mathrm{MPa})$ and superior to MR and FJ. KC was statistically equal to MR (av. $77.71 \mathrm{MPa}$ ) and superior to FJ. MR was similar to FJ (av. $64.50 \mathrm{MPa}$ ) statistically. FJ cement (av. $64.50 \mathrm{MPa}$ ) showed the lowest CS average, and did not even attain the ADA recommendation for CS (minimum of $65 \mathrm{MPa}$ ). ${ }^{17}$

Farret et al. ${ }^{16}$ found no difference in the CS tests for Ketac Cem (52.4 MPa) and Meron (38.09 MPa). Our study was in agreement with that of Farret et al., ${ }^{16}$ insofar as it showed no statistical difference between MR (77.71 MPa) and KC (81.93 MPa) in CS tests.

The flexural strength (FS) test measures tensile, compressive and shear strengths simultaneously, thus reproducing oral environment conditions. ${ }^{22}$ $\mathrm{BL}$ and $\mathrm{MC}$ cements showed the highest values (av. 137.41 MPa and av. 53.41 MPa, respectively) for FS, and were statistically different between each other and in comparison to the other cements studied (Table 4). No statistical differences were observed among cements FJ (av. 20.72 MPa), MR (av. 25.84 $\mathrm{MPa}$ ) and $\mathrm{KC}$ (av. 20.50 MPa). The literature relates that the FS values for RMGIC are normally twice as high as those for conventional glass ionomers. ${ }^{23,24}$ This was confirmed in the present study for MC but not for FJ.

The findings of Millett et al. ${ }^{14}$ indicate that although there appears to be equivalence in the mean shear-peel bond strength of the band cements assessed, the fatigue properties of the conventional GIC, when subjected to simulated mechanical stress, seem inferior to those of the other cements (RMGIC and modified composite) for band cementation. ${ }^{14}$ This means that CGI band cementation is more reliable than the modified composite used in the Millet et al. ${ }^{14}$ study. Because of the different testing methods employed in the Millet et al. ${ }^{14}$ study versus those used in the present investigation, it would not be valid to draw any comparisons between the results obtained for either investigation.

Komori and Kojima ${ }^{11}$ describe RMGIC as a better alternative than polyacid-modified resins and CGIs, because of its excellent durability, good enamel adhesion and fluoride release/uptake capability. RMGICs are usually marketed in powderliquid form and require a manual mixing procedure critical to producing an adequate preparation. The development of a two-paste system such as FJ helps surmount this issue. ${ }^{11}$

After the band is cemented, the glass ionomer cement adheres to enamel and metal, causing possible failures mainly at the cement/band interface, probably due to its low cohesion force. ${ }^{10}$ In order to over- 
come this issue, sandblasting the band with aluminum oxide is recommended to increase the adhesion force. ${ }^{25}$

Modified resins such as BL have very little acidbase reaction and are less likely to ionically bond to enamel, compared to CGI. Gillgrass et al. ${ }^{10}$ found no clinical failure differences between $\mathrm{BL}$ and $\mathrm{KC}$; however, BL failed mainly at enamel/cement interfaces, and KC failed mainly at cement/band interfaces. Gillgrass et al. ${ }^{10}$ did not find any differences in white spot lesions between BL and KC.

It seems prudent when choosing a material for band cementation not to consider mechanical properties as isolated factors. Comparisons of laboratory tests for the materials used in this study may not reflect a clinical situation appropriately. For example, polyacid-modified composites could fail without cement breakage, due to their low adhesion to enamel. ${ }^{10}$ This kind of failure is uncommon with CGIs or RMGICs because of their high adhesion to met-

\section{References}

1. Flores-Mir C. Bonded molar tubes associated with higher failure rate than molar bands. Evid Based Dent. 2011 Sep;12(3):84.

2. Millett D, Mandall N, Hickman J, Mattick R, Glenny AM. Adhesives for fixed orthodontic bands. A systematic review. Angle Orthod. 2009 Jan;79(1):193-9.

3. Millett DT, Glenny AM, Mattick RCR, Hickman J, Mandall NA. Adhesives for fixed orthodontic bands. Cochrane Database Syst Rev. 2007 Apr 18;(2):CD004485.

4. Millett DT, Duff S, Morrison L, Cummings A, Gilmour WH. In vitro comparison of orthodontic band cements. Am J Orthod Dentofacial Orthop. 2003 Jan;123(1):15-20.

5. Wilson AD, Paddon JM, Crisp S. The hydration of dental cements. J Dent Res. 1979 Mar;58(3):1065-71.

6. Kerby RE, Knobloch L, Thakur A. Strength properties of visible-light-cured resin-modified glass-ionomer cements. Oper Dent. 1997 Mar-Apr;22(2):79-83.

7. Li J, Betzen M, Sundström F. Strength and setting behavior of resin-modified glass ionomer cements. Acta Odontol Scand. 1995 Jan;53(5):311-7.

8. Palmer G, Jones FH, Billington RW, Pearson GJ. Chlorhexidine release from an experimental glass ionomer cement. Biomaterials. 2004 Oct;25(23):5423-31.

9. Youn Y, Lee Y, Lee D, Kim N, Lim Y. Effect of surface treatment and type of cement on the retentive strength of orth- al and enamel; however, failures may be observed upon cement cohesion breakage. The mechanical adaptation of a band to the tooth structure is as important as the selection of materials, since the band will help support the occlusional forces, and will no longer have to rely solely on the mechanical properties of the cements used.

\section{Conclusions}

According to the laboratorial strength tests performed, it can be concluded that:

a. Diametral tensile test: BL presented the highest strength, and MC had the second highest average. KC presented the lowest average results.

b. Compressive test: BL presented the highest strength. FJ had the lowest results, and did not attain the ADA recommendation.

c. Flexural test: BL presented the highest strength. $\mathrm{MR}, \mathrm{FJ}$ and $\mathrm{KC}$ were equivalent and inferior to $\mathrm{BL}$ and $\mathrm{MC}$. odontic bands on gold alloy crowns. Am J Orthod Dentofacial Orthop. 2007 Dec;132(6):728.e9-14.

10. Gillgrass TJ, Benington PCM, Millett DT, Newell J, Gilmour WH. Modified composite or conventional glass ionomer for band cementation? A comparative clinical trial. Am J Orthod Dentofacial Orthop. 2001 Jul;120(1):49-53.

11. Komori A, Kojima L. Evaluation of a new 2-paste glass ionomer cement. Am J Orthod Dentofacial Orthop. 2003 Jun;123(6):649-52.

12. Mccabe JF. Resin modified glass ionomers. Biomaterials. 1998 Apr;19(6):521-7.

13. Xu X, Burgess JO. Compressive strength, fluoride release and recharge of fluoride releasing materials. Biomaterials. 2003 Jun;24(14):2451-61.

14. Millett D T, Cummings A, Letters S, Roger E, Love J. Resinmodified glass ionomer, modified composite or conventional glass ionomer for band cementation- an in vitro evaluation. Eur J Orthod. 2003 Dec; 25(6):609-14.

15. International Organization for Standardization. ISO Standard 4049. Dentistry - Polymer-based filling, restorative and luting materials. Genebra: ISO; 2000.

16. Farret MM, Lima EM, Mota EG, Oshima HMS, Barth $\mathrm{V}$, Oliveira SD. Can we add chlorhexidine into glass ionomer cements for band cementation? Angle Orthod. 2011 May;81(3):496-502. 
17. American Dental Association. Council on Dental materials, Instruments, and Equipment. ANSI/ADA specification $\mathrm{n}^{\circ} 66$ for dental glass ionomer cements. J Am Dent Assoc. 1989 Jul;119(1):205.

18. Mckinney JE, Antonucci JM, Rupp NW. Wear and microhardness of glass-ionomer cements. J Dent Res.1987 Jun;66(6):11349.

19. Dental Standards Committee, BS 6039. British Standard Specification for Dental Glass Ionomer Cements. British Standard Institution; 1981. $12 \mathrm{p}$.

20. Naasan MA, Watson TF. Conventional glass ionomers as posterior restorations. A status report for the American Journal of Dentistry. Am J Dent. 1998 Feb;11(1):36-45.
21. Wang L, D’Alpino PHP, Lopes LG, Pereira JC. Mechanical properties of dental restorative materials: relative contribution of laboratory tests. J Appl Oral Sci. 2003 Sep;11(3):162-7.

22. Ban S, Anusavice KJ. Influence of test method on failure stress of brittle dental materials. J Dent Res. 1990 Dec;69(12):1791-9.

23. Wilson AD. Resin-modified glass-ionomer cements. Int J Prosthodont. 1990 Sep-Oct;3(5):425-9.

24. Xie D, Brantley WA, Culbertson BM, Wang G. Mechanical properties and microstructures of glass-ionomer cements. Dent Mater. 2000 Mar;16(2):129-38.

25. Mennemeyer VA, Neuman P, Powers JM. Bonding of hybrid ionomers and resin cements to modified orthodontic band materials. Am J Orthod Dentofacial Orthop. 1999 Feb; 115(2):143-7. 